\title{
Web interfaces to enhance CAL materials: case studies from law and statistics
}

\author{
David Grantham* and Neville Hunt** \\ *School of International Studies and Low, Coventry University, \\ **School of Mathematical and Information Sciences, Coventry University, \\ email:d.grantham@coventry.ac.uk
}

One impact of the 'information age' is that a variety of new learning resources have become available to both students and tutors. Using these resources effectively and with a sound pedagogical basis presents a whole array of issues for teaching professionals. In this paper the authors describe the development and implementation of a Web interface to existing computer-based learning materials in an attempt to enhance the student learning experience. Although the innovations occurred in two very different disciplines statistics and law - there are common lessons to be learned about the process of learning and the use of technology.

\section{Introduction}

Both authors were seconded part-time to the Coventry University Teaching and Learning Task Force in the autumn of 1997. There are two main driving forces behind this Task Force. The first is the changing context of higher education, where increasing numbers of students, the shrinking unit of resource and an increasing emphasis on learning and teaching is generating increasing concern about the quality of the student experience. The second is to test how far communications and information technology (C\&IT), highlighted in the Dearing Report (National Committee of Inquiry into Higher Education, 1997), could provide an important vehicle for more successful learning. At the same time there is an ongoing expansion of global learning resources available through the Internet. Harnessing these resources in a way that will enrich student learning became a focal point for both projects.

The authors come from two very different subject areas and, since law is not taught to statisticians nor statistics to lawyers, their paths would not normally have crossed. However, Coventry University's Task Force is divided into 'theme groups' and it is in such a group 
that the authors came to realize that their individual projects share some important common concerns and objectives. This article identifies those concerns and describes how the authors set about designing an electronic learning environment to deal with them. Both projects take existing CAL software (the 'basic packages', IOLIS for law and DISCUS for statistics) as their starting point and both aim to identify clearly, through evaluation, the perceived weaknesses in that software. Through an ongoing process of reflection, discussion, development and experimentation the authors have attempted to address these deficiencies before the evaluation stage again triggers a cycle of curriculum development.

\section{Methodology}

We are both engaged in the kind of critical and self-reflective enquiry described by Carr and Kemmis (1986) and Schon (1987) and falling under the general rubric of 'action research'. Conscious of the need to solve what we both perceived as a problem with current electronic resources in our respective fields, we were led to question the pedagogy that appeared to underpin them. Action research can, and in our case did, set in motion an enquiry into the very nature of teaching and learning and into the inner structure of our subjects. As McKernan (1996) observes: 'The professional teacher must have an answer to those who ask the question "What is the purpose of teaching?" To my mind the purpose of teaching is to understand the nature of knowledge' (p. 48).

Our efforts to produce a meaningful learning environment made us question the essential nature of our disciplines. We cannot say that we have found all the answers but, in any case, action research is 'cyclical' and we continue to develop our work over time and in the light of our reflection along the discuss-design-test-review continuum.

Another feature of action research; described by Kemmis and McTaggart (1988), is that it is collaborative, encouraging colleagues to share the issues; processes and fruits of the research. Support from other colleagues in the Task Force, both technical and pedagogical, was a crucial part of both the 'reflective' and 'action' stages of the process. Both authors are committed to conveying to interested colleagues the results of their projects and to coaching them in the technical aspects of the developments. This is an important stage in disseminating the innovation as well as maintaining the momentum of change. Action research also provides a sound platform for continuing professional development and we are both keen to make ever closer links between the theory and practice of learning and teaching, one of the hallmarks of the 'extended professional' referred to by Hoyle (1980).

\section{Critiques of the basic packages}

Introduced in 1995, IOLIS is a computer-assisted learning package commonly referred to as 'courseware' and authored by leading academics under the auspices of the Law Courseware Consortium, based at the University of Warwick. Features of IOLIS have been described elsewhere (Widdison, 1995; Moodie, 1997; Paliwala, 1998) but can be summarized as follows:

- an easy to use and powerful navigation system;

- self-test questions with feedback;

- excellent resource books with leading case reports and some leading articles; 
- self-paced learning;

- an increasingly wide range of subjects or modules;

- a scrapbook and copying/printing facility;

- twice yearly updates.

DISCUS (Discovering Important Statistical Concepts Using Spreadsheets) comprises a set of eight Microsoft Excel workbooks, accompanied by paper-based exercises, covering a selection of topics in elementary statistics. Originally developed at Coventry University in 1994, DISCUS site licences have since been purchased by more than 250 schools, colleges and universities. Hunt (1996) details the advantages of using spreadsheets in the teaching of statistics. The main benefits of DISCUS are:

- interactive demonstrations, simulations and dynamic graphics;

- opportunities for customization by the teacher;

- familiar user interface;

- emphasis on concepts rather than techniques;

- transparency of the software to students.

We both shared some concerns about the limits on learning that were revealed in these packages. Separate evaluations were carried out which were aimed at clearly identifying these limits so that there was a sound basis for further development. This revealed a number of common concerns that needed to be addressed.

\section{Surface learning}

Much has been researched and written on the virtues of deep learning (Marton and Saljo, 1976; Ramsden, 1992). Certain forms of teaching and learning in higher education, including electronic learning, can tend to push students towards a 'water boatman' approach to learning, i.e. skipping over the surface instead of looking more closely at what might lie underneath. Whereas the basic packages did encourage some deeper learning there is a tendency either to make this optional (an economic analysis of the law in parts of IOLIS, for example) or not to ask 'hard' questions where such questions might have been asked.

Experience of using DISCUS in teaching revealed a similar tendency to 'click and forget'. It was common for students to 'complete' a whole workbook in a matter of minutes without having properly engaged with the exercises. This is partly a fault of the exercises themselves, which tend to pose open questions without a unique or concise answer. Hence students can think they have answered a question without appreciating its full implications. However, it was always intended that DISCUS would be used in small laboratory classes in which the teacher would provoke discussion and encourage students to stop and think about their work. Now, with a dwindling staff resource, this is no longer practicable.

\section{Lack of context}

IOLIS deals only briefly with contextual concerns, e.g. the medical context of psychiatric injury. This can tend to rob the topic of its wider meaning (Grantham, 1985) and is part of an ongoing debate amongst academic lawyers about the limits of 'black letter' law. Those 
who argue for law students to know more than just legal principles and rules would find IOLIS 'patchy' in its approach to issues involving wider questions than the symmetry, or otherwise, of legal doctrine.

In statistics education it has long been recognized that students learn more from applying knowledge to real applications than by dealing with contrived or artificial 'toy' data (Singer and Willett, 1990). With the exception of a widely appreciated lottery simulation, in DISCUS the emphasis was more on theoretical statistical concepts than practical applications.

\section{Undue seriousness}

In the experience of both authors there is a truism, frequently neglected in these serious times, that if you can laugh then the chances are that you will also learn. There is more than a grain of truth in the words of Jack Point, the jester in The Yeoman of the Guard (Act I) who says he can 'trick you into learning with a laugh'. If the learning can also be entertaining then the chances are it will more readily remain in the mind of the student.

Certainly, some aspects of law contain their own humour. Law students have little difficulty in remembering the case about the lady who got locked in a lavatory, for example, and usually remember with a wry smile the case of the defective coupling. However, whilst having some of this natural humour, IOLIS does tend to be rather 'flat'. Although extremely colourful, DISCUS too suffered from a rather austere approach - heightened by the fact that nobody has ever been known to win the jackpot in the lottery simulation!

\section{Linking with prior learning}

It has been powerfully argued that the most important thing about learning is what the student already knows (Ausubel, Novak and Hanesian, 1978; Entwistle and Entwistle, 1992). IOLIS tends not to link with any prior learning outside the immediate topic area being studied, neither does it draw attention to any learning that ought to be embedded before embarking on new areas of study. Each DISCUS exercise sheet is prefaced by a 'What you need to know' list, but no resources are provided to cater for a student with a deficiency in this assumed knowledge.

\section{Dialogue and feedback}

IOLIS requires the students to attempt exercises and then provides instant feedback on their efforts. This certainly meets some of the criteria set out by Laurillard (1993) for effective electronic learning environments. What IOLIS fails to do is to identify why a student may have misunderstood a concept or rule. Thus, the student may go on to get the 'right answer' but still may not have understood how they got there! Real learning will not have taken place. It has been well argued that that this kind of deep learning can only take place in a truly interactive setting where there is some form of ongoing dialogue between the student and the tutor (Jones and Scully, 1996; 1998). Apart from assessment, such dialogue is the best evidence tutors have of the effectiveness of 'the teaching' having become 'the learning'. Frazer (1992) draws a simple but astute analogy with buying and selling:

Nothing is sold until it is bought, and nothing is taught until it is learnt. (p. 55)

In DISCUS no feedback is provided for the exercises, rendering it wholly unsuitable for self-learning. Indeed, a student may observe a phenomenon in one of the spreadsheets and 
wrongly conclude that it holds true in all cases, whereas in fact it may only apply to the special case being considered. As Reinhardt and Loftsgaarden (1979) point out, this is a particular problem with random simulations which, by their very nature, do not always show in a short run the results expected in the long run. Interaction with the package is therefore not only insufficient but potentially dangerous - some interaction with the teacher (whether virtual or real) is essential.

\section{Ability to customize and barriers to collaboration}

One real drawback of IOLIS is that the developers of the software determine the questions for the students. In the 'real' seminar or tutorial the questions that a particular tutor wants to ask his or her students are often highly 'individualized' and matched to the context of the learning situation at the time. An enhanced electronic learning environment should allow tutors to tailor questions to their individual preferences. IOLIS does have an annotation facility that tutors can use but it cannot deliver either graphics or hypertext.

DISCUS does allow teachers to customize their own copy of DISCUS. All the exercise sheets are provided in electronic form and teachers are given a password to unprotect the spreadsheets. However, any changes made to the teacher's copy of the software must somehow be mirrored on all copies of the software held at the institution. Where students have their own copy of DISCUS this is clearly highly inconvenient.

Neither package allows a team of tutors to collaborate in the design of new, enhanced or more specific, syllabus-relevant, material. In the case of DISCUS, because of the commercial implications, the software developers are reluctant to incorporate new ideas and material. Consequently the packages remain globally acceptable but, on their own, locally unsuitable. Moreover, tutors using the software do not have a sense of ownership of it, unless they happen to have been the authors or part-authors.

\section{Potential benefits and problems of Web interfacing}

After much debate about the most effective way of enhancing the basic packages, both authors became convinced that a Web interface would allow many of the weaknesses to be addressed. Among the perceived benefits of a Web-based approach are:

- unbounded multimedia links to thought-provoking sources can provide both the context and stimulation needed to develop skills of analysis, synthesis, evaluation and critique ('deep learning');

- learning can be self-tailored to suit the individual needs of each student - gaps in prior learning may be repaired by following hyperlinks to resources at a variety of levels ('individualized learning');

- choice over sites to be visited, either by following hyperlinks or through 'surfing', encourages the student to take more charge of his or her own learning ('autonomous learning');

- online discussions (like 'legal forum') allow contributions from all participants, especially from those who would otherwise be reluctant to speak in traditional settings ('participative learning'); 
- tutors can take advantage of new electronic sources by linking them directly to Web pages;

- material can be easily revised by editing the relevant Web pages without the need for new production runs of disks/CDs;

- learning is not limited in time or place.

We could also foresee potential weaknesses in the Web-based learning environment which had to be addressed in the Web page design, although other problems did not really surface until early pilot evaluations. These could be broadly categorized as pedagogical or technical. Pedagogical problems can be summarized as follows:

- some questions may not be suitable for electronic discourse and are better left for faceto-face seminars or tutorials;

- unless links to other Web resources significantly add value to student learning, students will become frustrated and lose interest;

- there is a danger that students will waste study time on visiting irrelevant sites, becoming distracted from the task in hand;

- some students may not want to be autonomous and prefer to be 'spoon-fed' with what they believe they need to know - this issue arises with traditional forms of learning and needs to be carefully handled by the tutor;

- if online discussions are not carefully managed, both in terms of getting useful student contributions and the timing and nature of tutor interventions, they can easily become no more than general chat-shops.

Technical problems can be summarized as:

- moving to Web-based learning places different demands on campus ICT facilities students are likely to spend longer online placing a greater strain on both workstations and Internet connections;

- it is not easy to create a seamless interface and trouble-free navigation between the Web-based material and the basic package;

- links to other Web resources may be unreliable - sites can move or disappear altogether.

It was evident to both of us from the outset that it would be impossible to find solutions to all these issues at the first attempt. Rather, we resolved to tackle the pedagogical issues and some of the technical matters by means of a 'design and test' approach. Thus two new packages were born, IOLISplus (Grantham, 1999) and VOLUME. Both new packages were designed using Microsoft Front Page 98 which builds in navigation between pages automatically and provides a variety of graphic themes for backgrounds, buttons and banners to give pages a consistent look and feel. Additional images, animations, cartoons and quotations are used to make the pages light and readable. Also, the packages provide numerous hyperlinks to external sources of relevant materials.

\section{IOLISplus}

IOLISplus currently comprises 25 Web pages covering three areas of the law of tort (general introduction, nuisance and psychiatric injury), although more pages are 
being added as they are designed and tested. The site may be viewed at http://home.edu.coventry.ac.uk/IOLISplus/. All of these pages are linked directly to IOLIS and supplement IOLIS exercises with tutor-generated questions linked directly to the relevant pages of IOLIS. Most of these questions, tailored to the lecture and seminar programme, require a better understanding of the matters being studied in IOLIS and are very much part of the author's strategy of promoting deeper learning. Students could easily 'skip over' these harder questions, of course, but they will inevitably crop up again in online discussions.

Animations, flow charts and graphics attempt to add interest and humour so that flat text does not dominate the page. Graphics are sometimes used as 'picture clues' to help students remember prior learning or to provide a trigger to understanding a particular concept or issue. Early piloting suggests that animated graphics not only amuse the students but are also a very powerful medium for learning. Hypertext links to a variety of online resources provide more context for the law being studied, providing a more comprehensive view of the issues involved. In particular, there are now two electronic law journals (Journal of Information Law and Technology and Journal of Current Legal Issues) which have been usefully linked to the appropriate IOLISplus web pages. Decisions of the House of Lords and the Court of Appeal are now also available on the Internet and these too have been linked to IOLISplus pages at various points.

An area of study in an IOLISplus Web page begins with 'What should already be known'. This lists the essential prior learning required before embarking on the new learning. Of course, there is no guarantee that the student will check out this learning, but if they get stuck in trying to understand new material then they can backtrack to earlier pages in IOLISplus or IOLIS. Another feature helping to move the student along is 'Frequently Occurring Misunderstandings' (FOMs) which are based on the author's experience of seminar work and assessing coursework and examinations. If they wish, a student can quickly navigate to these via hypertext before looking at the rest of the page. Becoming aware of these pitfalls before intensive study could enable the learner to avoid some of the more well-trodden legal byways and cul-de-sacs. A typical IOLISplus screen layout is shown in Figure 1.

If students were to interface between the IOLISplus web pages and IOLIS then a simple navigation system was needed. Having each of the two applications in separate 'frames' on one screen was tried but this caused problems when IOLIS required the student to complete an exercise. The whole of the text of the exercise needed to be viewed and this was not always the case. Where multi-choice answers were given then only part of the page could be viewed in the active window so that the student could not see all the available choices. After many messy tries at solving this problem it was decided that the most effective solution was to have separate screens, allowing easy navigation by using minimizing and maximizing buttons.

One of the most challenging design issues was to construct the technical 'how to use the total package' student guide pages. It meant using a combination of graphics, animations, icons and text carefully to take the novice student on a step-by-step journey through the processes for navigating, minimizing pages and following hyper links to external Web sites. Although this might look trite to the experienced 'net surfer' it proved a long task to ensure that the instruction was both logical and understandable. 


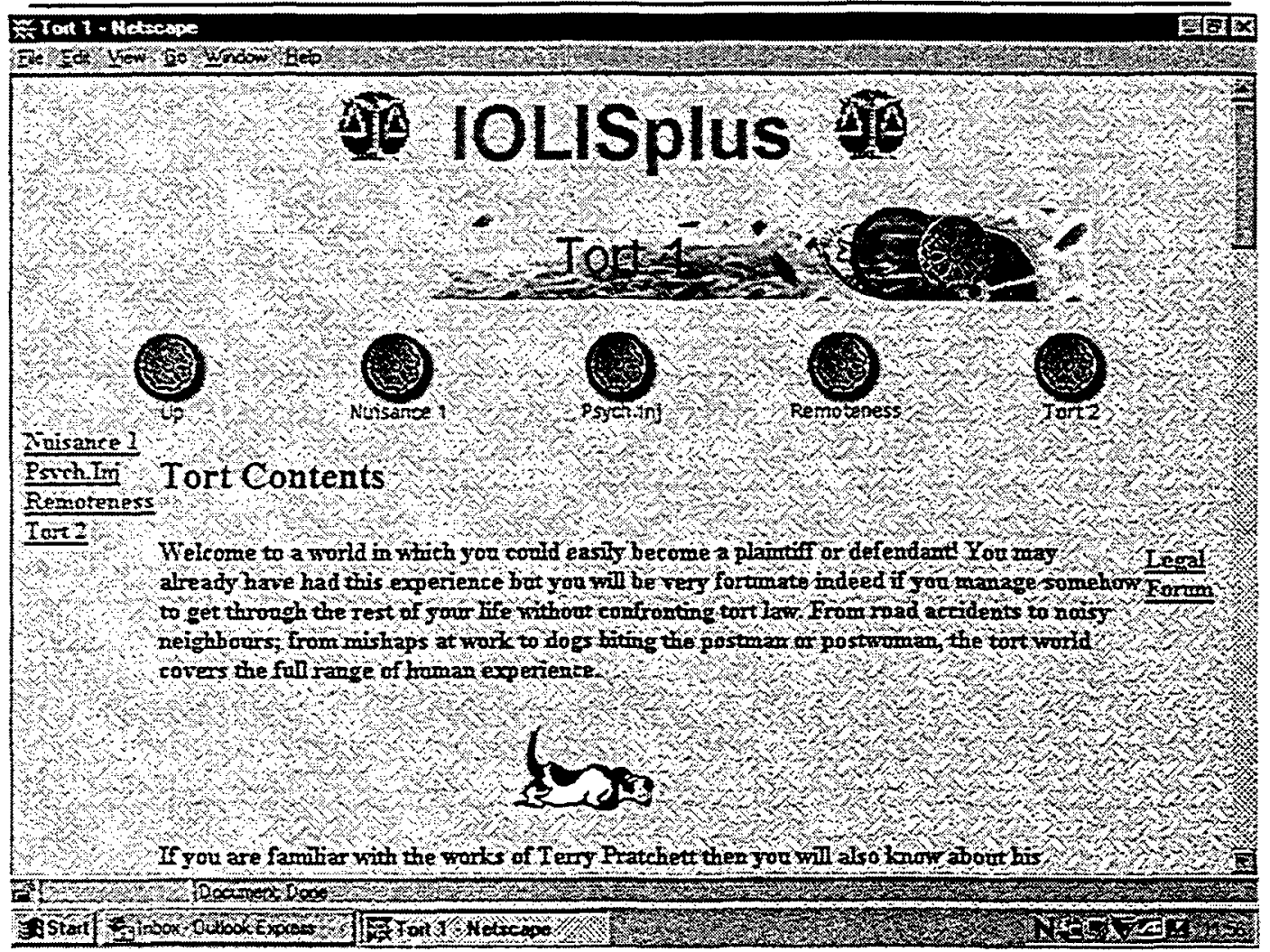

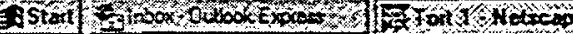

Figure 1: Typical IOUSplus screen loyout

A most significant development has been the creation of a 'legal forum' linked directly to the IOLISplus questions. Included as a facility in Front Page 98 this automatically produces an online discussion area where tutors and students can communicate with each other. Stringing together a discussion on a question or topic is also embedded in the software so that a student or tutor can follow the development of an argument or response. Students can test out ideas and learning with each other before 'posting' a response to the 'legal forum'. Tutors can monitor postings and intervene when the discussion is going off task or is simply flagging and in need of more stimulus.

\section{The VOLUME package}

The Web-based version of DISCUS is called VOLUME (Versatile Open Learning Using Microsoft Excel) and can be found at http://home.edu.coventry.ac.uk/Volumel. At the time of writing, three of the eight DISCUS units have been developed as VOLUME modules for use over the Web. Each module comprises a series of about five to ten interactive spreadsheet-based activities supported by pages of background text material. The pages and spreadsheets are all linked to a home page using standard FrontPage navigational facilities.

Unlike the difficulties faced by IOLISplus, VOLUME benefits from the seamless interface that exists between Microsoft Excel and the Internet Explorer browser. The original 


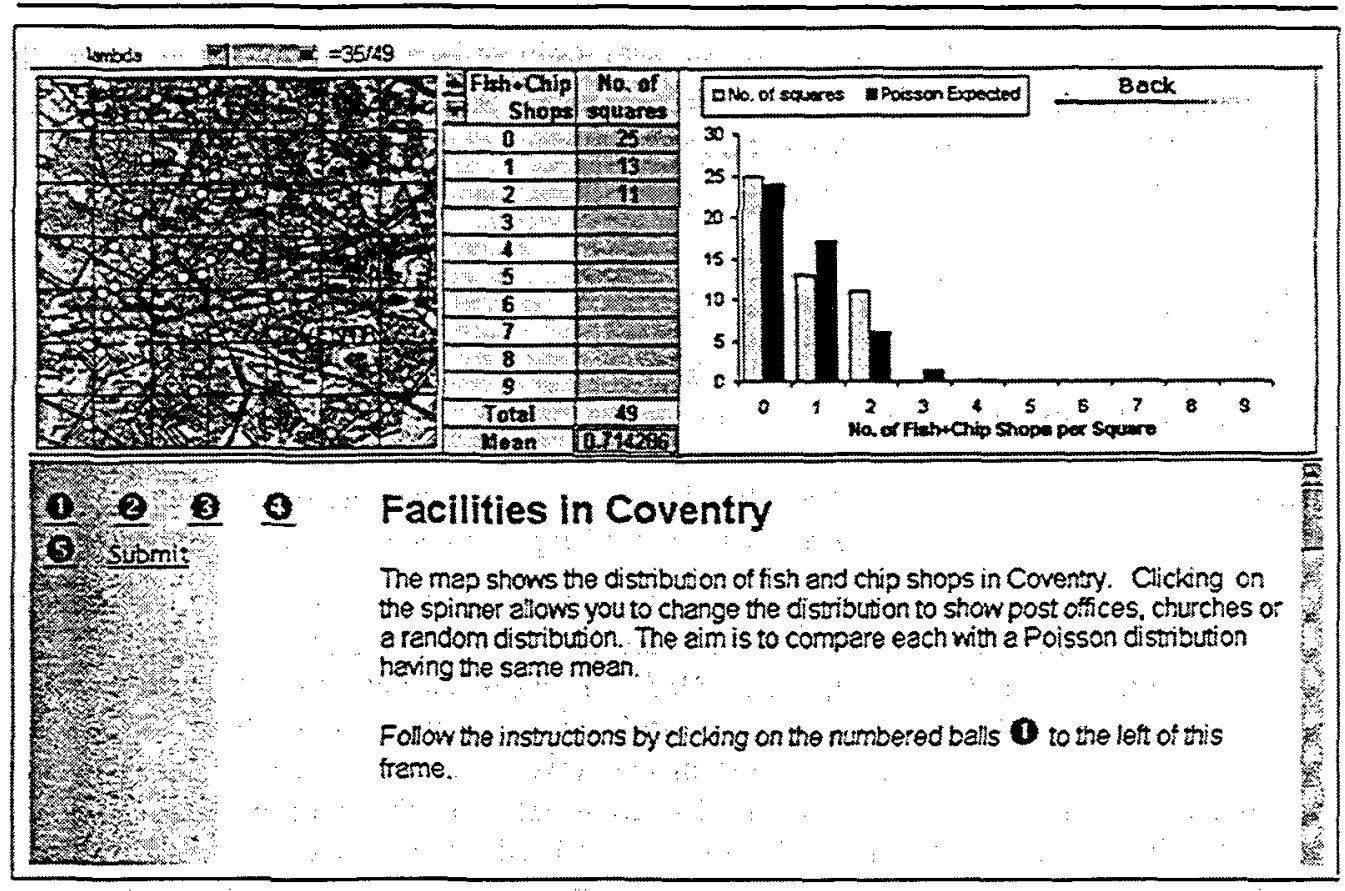

Figure 2: Typical VOLUME screen loyout

DISCUS spreadsheets can be viewed within the browser with only minor modifications. Moreover, hyperlinks can be placed directly onto the spreadsheets to link them with other Web pages. A standard VOLUME screen layout is shown in Figure 2. Unlike IOLISplus a frames layout has been employed on many pages, with the spreadsheet visible in the upper frame and exercises in the lower frame.

VOLUME incorporates background support material on both theory and applications, enabling the package to be used for individual study. It also provides links to selected external Internet sites which have been subject to prior evaluation by the authors. The sheer volume of material now available on the Web means that an important role of the tutor is to seek out those sites which will best supplement - rather than duplicate - existing local resources.

The paper-based DISCUS worksheets have been replaced by exercises that require the student to enter their answers onto an online form. Once an exercise is complete the student may submit the form and receive instant electronically-generated feedback. The FrontPage software automatically stores the submitted answers in a secure directory on the server together with the date, the time, the identity of the user and the location of their computer. This information is extremely valuable, enabling the tutor to monitor the progress of each student and identify those who are not engaging with this aspect of the learning process. Although the principal aim here is formative self-assessment, in some exercises it may be appropriate to withhold the feedback and use the student's responses as part of the summative assessment.

Coventry University has made the generous decision to allow the VOLUME modules to be freely accessible over the Internet. This release from commercial considerations makes it 
much easier for the authors to accept contributions from colleagues, both within the institution and elsewhere, so that the package has the potential to grow almost without restriction. Equally, colleagues have the freedom to write their own Web pages in their own style and simply include links to selected pages of the VOLUME modules, without having to adopt the whole package.

\section{Evaluation}

A critical component of the action research cycle is the evaluation and review stage of the process. Sometimes referred to as 'critical trialling' (Davis, 1981) it is the anvil upon which the workpiece (in this case the prototype IOLISplus and VOLUME) is knocked into shape. We had to let our students get their hands on our work and test it for pedagogic and technical bugs. If these were revealed then, in ICT jargon, they had to be 'fixed'.

Piloting and evaluation by students of the IOLISplus web pages took place in November 1998. This worked out quite well since they were about to study psychiatric injury and this had been chosen as the topic for the first IOLISplus pages. Two groups took part, one fulltime seminar group (12 students) and one part-time (evening) group (18 students). Something of a technical disaster struck the first session. The server could not cope with large numbers of students seeking access simultaneously and soon only cached copies of IOLISplus were available. Primitive communication had to be resorted to with the tutor visiting each workstation in turn to check on progress. However, despite this, there was an undoubted 'buzz' about the groups. Inexperienced 'surfers' had been helped by the 'Web-wise' and there was valuable collaboration at the subject and technical levels. Some of the tutor-set questions sparked off an interesting debate on the problems of proving that a psychiatric injury had occurred - one student finding time to surf the Internet for the Web site of the American Psychiatric Association. Others, having found and read part of a linked electronic journal article, were embroiled in a discussion about the current absurdities in the law. These were clear indications that, despite the technical glitches, at an educational level all was well.

On investigating the possible reasons for file server failure it was revealed that there were just simply too many active hyperlink graphics ('hotspots') on a single page! Drastic redesign of the IOLISplus Web to reduce hyperlinks to a minimum resolved the difficulty. Another problem arose when a student wished to go back to an earlier page of IOLIS, since IOLIS pages only number forward! This was subsequently overcome by navigating back to the full list of work books on IOLIS and starting again at the beginning of the relevant section or file, but the inexperienced student may find this a hurdle.

The second session went far more smoothly with interesting postings to the online discussion forum, which ran well after a hesitant start. Evidence of deep learning was provided by some students comparing their own personal experiences of accidents and subsequent trauma to the relevant but rather rigid and technical legal rules. Others were able to embark on a critique, using an article linked from another Web site. Although the time set for the session passed very quickly, all the students went on well beyond this time.

Written feedback using a standard questionnaire was generally very positive and most 90 per cent of a total of $\mathbf{3 0}$ students) found the exercise interesting or very interesting. Only two students had had initial difficulties with navigation. Opinions on whether they preferred electronic learning or traditional learning split both groups. Five students preferred elec- 
tronic learning, eight preferred traditional learning and ten wished for a combination of both.

There were also a number of unforeseen teething problems with the prototype VOLUME module. An evaluation of initial piloting with students took place in April 1998 and a number of problems were identified:

- Extraordinarily, it emerged that the spreadsheets would only open the first time they were accessed, any subsequent return causing the browser to crash. This was eventually overcome by placing the navigation buttons on the spreadsheet itself, but some problems remain with apparent conflicts between the server and cache copies of the spreadsheet files.

- The integration of Excel and Internet Explorer generates many annoying warning messages. In particular, if a spreadsheet contains macros (mini programs), the user is warned that macros may harbour viruses and they should not open the spreadsheet unless they are sure it is from a reliable source. In tests students steadfastly refused to open these spreadsheets following the warning. Consequently, wherever possible, the spreadsheets have been redesigned so as not to include macros.

- It was surprising to discover how much store students set on being able to print out the VOLUME pages. The page set-up and colour scheme of the spreadsheets had to be adjusted to ensure a clear printout could be obtained.

Despite these troublesome features student reaction was generally very positive and provided an encouragement to proceed with further modules. Several students commented on how they liked to be able to experiment and pose 'What if ...' questions, a clear sign that they were engaging well with the module. Students also liked the ability to receive instant feedback on their responses, unlike traditional assessments where, by the time the feedback is received, the student has forgotten what they submitted! The requirement for students to enter an answer to each question seemed to encourage them to stop and think, rather than 'click and forget'. Despite efforts to include more realistic contexts for the statistics, some students complained that they were not interested in babies, sport, etc. We had deliberately not made the contexts subject-specific, but clearly there is a need to align contexts more with the student culture. Most gratifying was the common response that 'it was fun', which suggests that students might return voluntarily for a second helping rather than having to be force-fed.

\section{Conclusion}

Our first tentative steps into cyberspace were accompanied by a healthy scepticism and much uncertainty. However, we are both now far more confident that a carefully designed electronic learning environment has a great deal to offer. It has the potential to address a number of the current pedagogical concerns, not least of which is providing a learning environment in which the student can make more sense of the subject. Given the appropriate technological infrastructure we both believe that the kind of enhanced electronic learning environment provided by developments like IOLISplus and VOLUME can also address some of the resource issues currently facing higher education.

Together with the basic packages both IOLISplus and VOLUME can be used as a total learning environment, as a supplement to a lecture or seminar programme or as a revision 
programme. Except where students have to learn at a distance we are both certain that continued face-to-face contact with students is going to be just as important as it has always been. Naisbitt (1984) argues that new technology needs to be balanced by more of the human touch:

Whenever institutions introduce new technology to customers or employees, they should build in a high touch component; if they don't, people will try to create their own or reject the new technology. (p. 43)

Continuing resource constraints, however, are likely to reduce contact time, rather than increase it. Enhanced electronic environments allow tutors to reconsider how they best use the available time. We are convinced that some 'mix' of electronic learning and face-to-face learning can produce a really worthwhile student experience in both our disciplines. If students can master the basic packages and contribute collaboratively and effectively to online discussions, or even just learn from following them, then any subsequent face-toface seminars should be 'quality' time. Matters of particular difficulty or interest can be explored in greater depth than would have generally been possible without prior electronic support. Whilst it is true that the same kind of prior learning could be had from text books, lecture notes and other conventional sources it is also true that such preparation is not tailored so specifically to the demands of a particular subject or module. Online discussions allow a dialogue between students, perhaps in 'action learning sets', and then with the tutor. More challenging topics might persuade the tutor to monitor discussion and intervene where students are clearly having difficulty. In our experience, such interactions are rarely found in conventional lectures.

However they, or similar developments, are deployed, the clients of the service (students) are likely to be demanding more for their increasing investment in their education. In particular, many of those who have their own hardware will expect to see modern C\&IT methods designed into their courses. Students will tend to spend more of their time surfing the Internet looking for material relevant to their studies. Valuable time can be wasted in such a search. It is far better that directly relevant and valuable resources should have already been identified by someone who has visited and evaluated these regions of cyberspace on a number of previous occasions.

Soon we hope to pass on what we have learned to interested colleagues in our respective disciplines. Design of Web pages can be undertaken by individuals or by teams of tutors within the same institution or even by tutors from different institutions who share similar learning aims and objectives. We are very much aware of the importance of creating the right conditions for this development and share the concerns of Main (1985) that there is:

a need for openness, co-operation, shared ownership and responsibility as underlying values for staff development. (p. 115)

There is so much scope for individual preference and professional constructive critique in Web page design that at least two or three of these objectives can be satisfied. On the other hand, the degree of openness depends heavily on the nature of the relationships between colleagues. However, such collaborative ventures would encourage the embedding of 'best practice' as well as extending Web design skills amongst wider groups of colleagues.

IOLISplus and VOLUME use current technology to create an electronic environment that 
addresses certain pedagogical issues and tries to provide a worthwhile experience for students of law and statistics. We have learned much from our adventures in cyberspace and how it can relate to our separate but demanding disciplines. Further development and evaluation is planned so our own learning goes on.

\section{References}

Ausubel, D. P., Novak, J. S. and Hanesian, H. (1978), Educational Psychology: A Cognitive View, New York: Holt, Rinehart \& Winston.

Carr, W. and Kemmis, S. (1986), Becoming Critical: Education, Knowledge and Action Research, London: The Falmer Press.

Davis, E. (1981), Teachers As Evaluators, Sydney: George Allen and Unwin.

Entwistle, A. C. and Entwistle, N. J. (1992), 'Experiences of understanding in revising for degree examinations', Learning and Instruction, 2, 1-22.

Frazer, M. (1992), 'Promoting learning', in Barnett, R. (ed.), Learning to Effect, Buckingham: Society for Research into Higher Education and Open University Press, 55-65.

Grantham, D. J. (1985), "Beyond the letter of the law: an evaluation of "A" level law courses', MA dissertation, University of Sussex.

Grantham, D. J. (1999), 'IOLISplus - extending the electronic learning environment', Journal of Information Law and Technology, 1999, 1, http://www.law.warwick.ac.uk/jilt/99-1/grantham.html.

Hoyle, E. (1980), 'Professionalisation and deprofessionalisation in education', in Hoyle, E. and Megarry, J. (eds.), World Yearbook of Education: Professional Development of Teachers, London: Kogan Page.

Hunt, D. N. (1996), 'Teaching statistical concepts using spreadsheets', Proceedings of the 1995 Conference of the Association of Statistics Lecturers in Universities, 1-3. Teaching Statistics Trust, http://www.mis.coventry.ac.uk/ nhunt/ASLU.htm.

Jones, R. and Scully, J. (1996), 'Hypertext within Legal Education', Journal of Information Law and Technology, 1996, 2, http://elj.warwick.ac.uk/jilt/cal/2jones/.

Jones, R. and Scully, J. (1998), 'Effective teaching and learning of law on the Web', Web Journal of Current Legal Issues, 1998, 2, http://webjcli.ncl.ac.uk/1998/issue2/jones2.html.

Kemmis, S. and McTaggart, R. (eds.) (1988), The Action Research Reader, Geelong: Deakin University Press.

Laurillard, D. (1993), Rethinking University Teaching, London: Routledge.

Main, A. (1985), Educational Staff Development, London: Croom Helm.

Marton, F. and Saljo, R. (1976), 'On qualitative differences in learning I: outcome and process', British Journal of Educational Psychology, 46, 4-11.

McKernan, J. (1996), Curriculum Action Research, London: Kogan Page. 
Moodie, P. (1997), 'Law courseware and IOLIS: assessing the present and constructing the future', Journal of Information, Law and Technology, 1997, 1, http://elj.warwick.ac.uk/jilt/cal/97_lmood/.

Naisbitt, J. (1984), Megatrends, London: MacDonald \& Co.

National Committee of Inquiry into Higher Education (1997), Higher Education in the Learning Society, London.

Paliwala, A. (1998), 'Co-operative development of CAL materials: a case study of IOLIS', Journal of Information, Law and Technology, 1998, 3, http://www.law.warwick.ac.uk/jilt/98-3/paliwala.html.

Ramsden, P. (1992), Learning to Teach in Higher Education, London: Routledge.

Reinhardt, H. E. and Loftsgaarden, D. O. (1979), 'Using simulation to resolve probability paradoxes', International Journal of Mathematical Education in Science and Technology, $10,2,241-50$.

Schon, D. A. (1987), Educating the Reflective Practitioner, San Francisco: Jossey-Bass.

Singer, J. D. and Willett, J. B. (1990), 'Improving the teaching of applied statistics; putting the data back into data analysis', American Statistician, 44, 3, 223-30.

Widdison, R. (1995), 'Law courseware: big bang or damp squib?', Web Journal of Current Legal Issues, 1995, 4, http://www.ncl.ac.uk/ nlawwww/articles4/widdis4.html. 